Research Article

\title{
Evaluation of Wind-Induced Response Bounds of High-Rise Buildings Based on a Nonrandom Interval Analysis Method
}

\author{
Xianglei Wei, An Xu $(\mathbb{D}$, and Ruohong Zhao $\mathbb{D}$ \\ Guangzhou University-Tamkang University Joint Research Center for Engineering Structure Disaster Prevention and Control, \\ Guangzhou University, Guangzhou, China \\ Correspondence should be addressed to An Xu; rocky-xu@qq.com
}

Received 24 April 2018; Accepted 5 September 2018; Published 1 October 2018

Academic Editor: Evgeny Petrov

Copyright (c) 2018 Xianglei Wei et al. This is an open access article distributed under the Creative Commons Attribution License, which permits unrestricted use, distribution, and reproduction in any medium, provided the original work is properly cited.

\begin{abstract}
The traditional wind-induced response analysis of high-rise buildings conventionally considers the wind load as a stationary stochastic process. That is, for a certain wind direction angle, the reference wind speed (usually refers to the mean wind speed at the building height) is assumed to be a constant corresponding to a certain return period. Combined with the recorded data in wind tunnel test, the structural response can be computed using the random vibration theory. However, in the actual typhoon process, the average wind speed is usually time-variant. This paper combines the interval process model and the nonrandom vibration analysis method with the wind tunnel test and proposes a method for estimating the response boundary of the high-rise buildings under nonstationary wind loads. With the given upper and lower bounds of time-variant wind excitation, this method can provide an effective calculation tool for estimating wind-induced vibration bounds for high-rise buildings under nonstationary wind load. The Guangzhou East tower, which is $530 \mathrm{~m}$ high and the highest supertall building in Guangzhou, China, was taken as an example to show the effectiveness of the method. The obtained boundary response can help disaster prevention and control during the passage of typhoons.
\end{abstract}

\section{Introduction}

The conventional methods of wind-induced vibration of tall buildings are based on the basic assumption that wind loads are stationary random processes [1-4]. That is, assuming the reference wind speed of a certain wind direction is a constant. Combined with wind tunnel test data, this assumption can be used to calculate structural response and provide the peak response for a structural design [5]. An actual typhoon has obvious nonstationary characteristics. The average wind speed at the reference height of a building is time-varying rather than constant. The conventional structural windinduced response analysis framework cannot effectively predict structural response at each moment when a typhoon passes. In actual operation, this nonrandom vibration analysis method is used to predict typhoon wind speed from a small sample and obtain the upper and lower boundaries of the typhoon. Combined with high-frequency force balance (HFFB) wind tunnel test data, the boundary values of structural response at each time instant can be predicted, and the boundary response of a building can be estimated to guide disaster prevention and control.

During a real typhoon, average wind speed at the reference height of a building is time-variant. Researchers have developed methods to estimate the response boundaries of a system subjected to nonstationary loads. Qiu and Elishakoff proposed a subinterval perturbation method for estimating the static displacement bound of structures with interval parameters [6]. Chen et al. [7] proposed a method to solve the static displacement problem with interval parameter structure uncertainty. Qiu and Wang used parametric perturbation methods to evaluate the dynamic response of structures with uncertain but bounded parameters [8]. Moens and Vandepitte proposed a method of 
interval sensitivity evaluation in the framework of general numerical interval analysis [9]. Verhaeghe et al. [10] proposed the concept of interval domains, considering static analysis of a structure with interval uncertainty using the finite element method. With the development of interval convex model theory, Jiang et al. $[11,12]$ proposed a nonrandom vibration analysis method for nonprobabilistic convex models. It is only necessary to know the boundary excitation information at an arbitrary time point rather than the exact probability distribution. The solution system is a responsive interval under uncertain excitation. This method reduces the dependence on large sample sizes and considers the correlation between interval variables and provides a new nonlinear interval programming method, which can be used to deal with uncertain optimization problems when there is a dependency relationship among interval variables. Gao et al. [13] proposed a mixed probability and interval reliability analysis method to solve engineering problems. Considering that uncertain factors widely exist in practical engineering, Wang et al. [14-16] proposed a novel methodology of reliability-based multidisciplinary design optimization under hybrid interval and fuzzy uncertainties, and a dimension-wise method and its improvement for multidisciplinary interval uncertainty analysis, and the methods of hybrid time-variant reliability estimation for active control structures under aleatory and epistemic uncertainties. These methods have important value in solving the uncertainty problem in practical engineering.

The HFFB technique is one of the most widely used techniques to evaluate effects of wind-induced vibration of tall buildings [17-22]. The nonrandom vibration theory of the interval process model is combined with HFFB wind tunnel tests to predict the boundary response, including displacement, velocity, and acceleration response, of highrise buildings subjected to nonstationary wind loads. Through a case analysis of Guangzhou East Tower (GZET), the feasibility of the method is examined.

\section{Methodology}

2.1. Interval Process Model. For an uncertain process $\{X(t), t \in T\}, T$ is the parameter set of time instant $t$. For any time instant $t_{i}(i=1,2, \ldots, n)$, if the possible values of $X\left(t_{i}\right)$ are within the interval $\left[X^{\mathrm{L}}(t), X^{\mathrm{U}}(t)\right]$, the process $\{X(t), t \in T\}$ is called an interval process model, denoted as $X^{\mathrm{I}}(t)$ [23]. For the interval process model $X^{\mathrm{I}}(t), X^{\mathrm{U}}(t)$, and $X^{\mathrm{L}}(t)$ are the upper and lower bound functions, respectively. The middle point function of $X^{\mathrm{I}}(t)$ and $X^{\mathrm{C}}(t)$, is defined as

$$
X^{\mathrm{C}}(t)=\frac{X^{\mathrm{U}}(t)+X^{\mathrm{L}}(t)}{2} .
$$

The half width function $X^{\mathrm{W}}(t)$ of the interval process model $X^{\mathrm{I}}(t)$ is defined as

$$
X^{\mathrm{W}}(t)=\frac{X^{\mathrm{U}}(t)-X^{\mathrm{L}}(t)}{2} .
$$

The variation coefficient function $\eta_{X}(t)$ of the interval process model $X^{\mathrm{I}}(t)$ is defined as

$$
\eta_{X}(t)=\frac{X^{\mathrm{W}}(t)}{X^{\mathrm{C}}(t)}
$$

For an interval process $X^{\mathrm{I}}(t)$, the self-correlation function between any two interval variables $X^{\mathrm{I}}\left(t_{i}\right)$ and $X^{\mathrm{I}}\left(t_{j}\right)$ at different times $t_{i}$ and $t_{j}$ is defined as $r_{X X}\left(t_{i}, t_{j}\right)$

$$
r_{X X}\left(t_{i}, t_{j}\right)=\frac{(1 / m) \sum_{p=1}^{m}\left(x_{i}^{(p)}-X_{i}^{C}\right)\left(x_{j}^{(p)}-X_{j}^{C}\right)}{W_{i}^{X} W_{j}^{X}},
$$

where

$$
W_{i}^{X}=\sqrt{(1 / m) \sum_{p=1}^{m}\left(x_{i}^{(p)}-X_{i}^{\mathrm{C}}\right)^{2}}
$$

$W_{j}^{X}=\sqrt{(1 / m) \sum_{p=1}^{m}\left(x_{j}^{(p)}-X_{j}^{C}\right)^{2}} ; x_{i}^{(p)}$ and $x_{j}^{(p)}$ are the values of the $p$ th sample function at time $t_{i}$ and $t_{j}$, respectively; and $X_{i}^{\mathrm{C}}$ and $X_{j}^{\mathrm{C}}$ are the values of the middle point function of $X^{\mathrm{I}}(t)$ at time $t_{i}$ and $t_{j}$, respectively.

2.2. Nonrandom Vibration Analysis Method. Based on the interval process model, Jiang et al. [23] proposed a nonrandom vibration analysis method. In this method, the timevarying uncertain excitation is treated as an interval process model, and the corresponding structural response is the interval form of the upper and lower boundaries. In practical applications, this nonrandom vibration analysis method, combined with HFFB technology, can estimate the structural response boundaries of tall buildings and give nonstationary reference wind speeds. This method requires only conventional wind tunnel tests which are carried out in a stationary wind field.

2.2.1. Under Deterministic Excitation. As shown in Figure 1, consider a simple single degree of freedom (SDOF) oscillator model, with mass $m$, spring stiffness $k$, damping coefficient $c$, and external force $F(t)$. The motion equation can be given in the form as follows:

$$
m \ddot{z}+c \dot{z}+k z=F(t)
$$

or

$$
\ddot{z}+2 \zeta \omega_{\mathrm{n}} \dot{z}+\omega_{\mathrm{n}} z=\frac{F(t)}{m},
$$

where $z, \dot{z}$, and $\ddot{z}$ are the displacement, velocity, and acceleration response for the first mode in each direction of the system, respectively. The natural frequency $\omega_{n}$ and damping ratio $\zeta$ are given by

$$
\begin{aligned}
\omega_{\mathrm{n}} & =\sqrt{\frac{k}{m}}, \\
c_{\mathrm{c}} & =2 m \omega_{\mathrm{n}}, \\
\zeta & =\frac{c}{c_{\mathrm{c}}},
\end{aligned}
$$




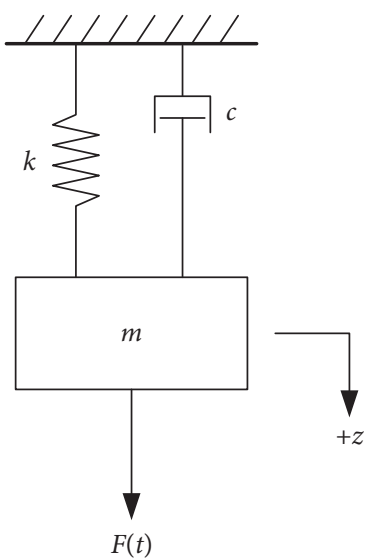

(a)

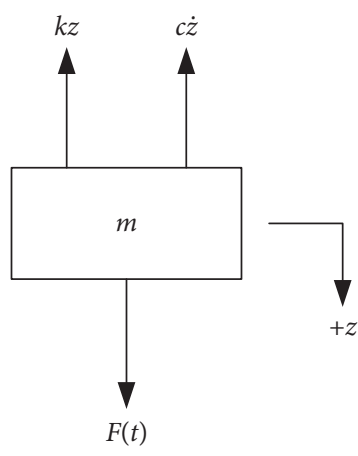

(b)

FIGURE 1: SDOF spring-mass-damper vibration system.

where $c_{\mathrm{c}}$ is the critical damping coefficient.

In this paper, the response of Equations (5) or (6) is solved using Duhamel's integral. Herein, the piecewise linear interpolation function [24] is first used to approximately fit the sequence of $F\left(t_{i}\right)$ (denoted as $F_{i}$ ), where the rate of change of $F(t)$ within arbitrary period of time is supposed to be linear. In this way, Duhamel's integral can be then applied to compute the response at time $t=t_{j}, j=1,2,3, \ldots, n$ :

$$
\begin{aligned}
z_{j}= & \frac{\Delta F_{j}}{k \Delta t_{j}}\left[\Delta t_{j}-\frac{2 \zeta}{\omega_{\mathrm{n}}}+e^{-\zeta \omega_{\mathrm{n}} \Delta t_{j}}\left\{\frac{2 \zeta}{\omega_{\mathrm{n}}} \cos \omega_{\mathrm{d}} \Delta t_{j}-\frac{\omega_{\mathrm{d}}^{2}-\zeta^{2} \omega_{\mathrm{n}}}{\omega_{\mathrm{n}}^{2} \omega_{\mathrm{d}}} \sin \omega_{\mathrm{d}} \Delta t_{j}\right\}\right] \\
& +\frac{F_{j-1}}{k}\left[1-e^{-\zeta \omega_{\mathrm{n}} \Delta t_{j}}\left\{\cos \omega_{\mathrm{d}} \Delta t_{j}+\frac{\zeta \omega_{\mathrm{n}}}{\omega_{\mathrm{d}}} \sin \omega_{\mathrm{d}} \Delta t_{j}\right\}\right] \\
& +e^{-\zeta \omega_{\mathrm{n}} \Delta t_{j}}\left[z_{j-1} \cos \omega_{\mathrm{d}} \Delta t_{j}+\frac{\dot{z}_{j-1}+\zeta \omega_{\mathrm{n}} z_{j-1}}{\omega_{\mathrm{d}}} \sin \omega_{\mathrm{d}} \Delta t_{j}\right],
\end{aligned}
$$

where $\Delta F_{j}=F_{j}-F_{j-1}, \Delta t_{j}=t_{j}-t_{j-1}$, and $\omega_{\mathrm{d}}=\omega_{\mathrm{n}} \sqrt{1-\zeta^{2}}$. The velocity $\dot{z}_{j}$ at time $t=t_{j}$ can be calculated as follows:

$$
\begin{aligned}
\dot{z}_{j}= & \frac{\Delta F_{j}}{k \Delta t_{j}}\left[1-e^{-\zeta \omega_{\mathrm{n}} \Delta t_{j}}\left\{\cos \omega_{\mathrm{d}} \Delta t_{j}+\frac{\zeta \omega_{\mathrm{n}}}{\omega_{\mathrm{d}}} \sin \omega_{\mathrm{d}} \Delta t_{j}\right\}\right] \\
& +\frac{F_{j-1}}{k} e^{-\zeta \omega_{\mathrm{n}} \Delta t_{j}} \frac{\omega_{\mathrm{n}}^{2}}{\omega_{\mathrm{d}}} \sin \omega_{\mathrm{d}} \Delta t_{j}+e^{-\zeta \omega_{\mathrm{n}} \Delta t_{j}}\left[\dot{z}_{j-1} \cos \omega_{\mathrm{d}} \Delta t_{j}\right. \\
& \left.-\frac{\zeta \omega_{\mathrm{n}}}{\omega_{\mathrm{d}}}\left(\dot{z}_{j-1}+\frac{\omega_{\mathrm{n}}}{\zeta} z_{j-1}\right) \sin \omega_{\mathrm{d}} \Delta t_{j}\right] .
\end{aligned}
$$

Equations (8) and (9) can be rewritten in the following form:

$$
\begin{aligned}
& z_{j}=A_{j} \Delta F_{j}+B_{j} F_{j-1}+C_{j} z_{j-1}+D_{j} \dot{z}_{j-1}, \\
& \dot{z}_{j}=\bar{A}_{j} \Delta F_{j}+\bar{B}_{j} F_{j-1}+\bar{C}_{j} z_{j-1}+\bar{D}_{j} \dot{z}_{j-1},
\end{aligned}
$$

where

$$
\begin{aligned}
A_{j}= & \frac{1}{k \Delta t_{j}}\left[\Delta t_{j}-\frac{2 \zeta}{\omega_{n}}+e^{-\zeta \omega_{\mathrm{n}} \Delta t_{j}}\left\{\frac{2 \zeta}{\omega_{\mathrm{n}}} \cos \omega_{\mathrm{d}} \Delta t_{j}\right.\right. \\
& \left.\left.-\frac{\omega_{\mathrm{d}}^{2}-\zeta^{2} \omega_{\mathrm{n}}}{\omega_{\mathrm{n}}^{2} \omega_{\mathrm{d}}} \sin \omega_{\mathrm{d}} \Delta t_{j}\right\}\right], \\
B_{j}= & \frac{1}{k}\left[1-e^{-\zeta \omega_{\mathrm{n}} \Delta t_{j}}\left\{\cos \omega_{\mathrm{d}} \Delta t_{j}+\frac{\zeta \omega_{\mathrm{n}}}{\omega_{\mathrm{d}}} \sin \omega_{\mathrm{d}} \Delta t_{j}\right\}\right], \\
C_{j}= & e^{-\zeta \omega_{\mathrm{n}} \Delta t_{j}}\left(\cos \omega_{\mathrm{d}} \Delta t_{j}+\frac{\zeta \omega_{\mathrm{n}}}{\omega_{\mathrm{d}}} \sin \omega_{\mathrm{d}} \Delta t_{j}\right), \\
D_{j}= & e^{-\zeta \omega_{\mathrm{n}} \Delta t_{j}} \frac{1}{\omega_{\mathrm{d}}} \sin \omega_{\mathrm{d}} \Delta t_{j}, \\
\bar{A}_{j}= & \frac{1}{k \Delta t_{j}}\left[1-e^{-\zeta \omega_{\mathrm{n}} \Delta t_{j}}\left\{\cos \omega_{\mathrm{d}} \Delta t_{j}+\frac{\zeta \omega_{\mathrm{n}}}{\omega_{\mathrm{d}}} \sin \omega_{\mathrm{d}} \Delta t_{j}\right\}\right], \\
\bar{B}_{j}= & \frac{1}{k} e^{-\zeta \omega_{\mathrm{n}} \Delta t_{j} \omega_{\mathrm{n}}^{2}} \sin \omega_{\mathrm{d}} \Delta t_{j}, \\
\bar{C}_{\mathrm{d}}= & -e^{-\zeta \omega_{\mathrm{n}} \Delta t_{j}} \frac{\omega_{\mathrm{n}}^{2}}{\omega_{\mathrm{d}}} \sin \omega_{\mathrm{d}} \Delta t_{j}, \\
\bar{D}_{j}= & e^{-\zeta \omega_{\mathrm{n}} \Delta t_{j}}\left(\cos \omega_{\mathrm{d}} \Delta t_{j}-\frac{\zeta \omega_{\mathrm{n}}}{\omega_{\mathrm{d}}} \sin \omega_{\mathrm{d}} \Delta t_{j}\right) .
\end{aligned}
$$

Rewriting Equation (10) in matrix form gives

$$
\left[\begin{array}{c}
z_{j} \\
\dot{z}_{j}
\end{array}\right]=\left[\begin{array}{cccc}
A_{j} & B_{j}-A_{j} & C_{j} & D_{j} \\
\bar{A}_{j} & \bar{B}_{j}-\bar{A}_{j} & \bar{C}_{j} & \bar{D}_{j}
\end{array}\right]\left[\begin{array}{c}
F_{j} \\
F_{j-1} \\
z_{j-1} \\
\dot{z}_{j-1}
\end{array}\right] .
$$


By using either Equations (10) or (12) repeatedly, the following recurrence sequences can be obtained:

$$
\begin{aligned}
{\left[\begin{array}{c}
F_{j} \\
F_{j-1} \\
z_{j-1} \\
\dot{z}_{j-1}
\end{array}\right] } & {\left[\begin{array}{ccccc}
1 & 0 & 0 & 0 & 0 \\
0 & 1 & 0 & 0 & 0 \\
0 & A_{j-1} & B_{j-1}-A_{j-1} & C_{j-1} & D_{j-1} \\
0 & \bar{A}_{j-1} & \bar{B}_{j-1}-\bar{A}_{j-1} & \bar{C}_{j-1} & \bar{D}_{j-1}
\end{array}\right]\left[\begin{array}{c}
F_{j} \\
F_{j-1} \\
F_{j-2} \\
z_{j-2} \\
\dot{z}_{j-2}
\end{array}\right] } \\
& =\mathbf{H}_{j-1}\left[\begin{array}{c}
F_{j} \\
F_{j-1} \\
F_{j-2} \\
z_{j-2} \\
\dot{z}_{j-2}
\end{array}\right],
\end{aligned}
$$$$
\left[\begin{array}{c}
F_{j} \\
F_{j-1} \\
F_{j-2} \\
z_{j-2} \\
\dot{z}_{j-2}
\end{array}\right]=\left[\begin{array}{cccccc}
1 & 0 & 0 & 0 & 0 & 0 \\
0 & 1 & 0 & 0 & 0 & 0 \\
0 & 0 & 1 & 0 & 0 & 0 \\
0 & 0 & A_{j-2} & B_{j-2}-A_{j-2} & C_{j-2} & D_{j-2} \\
0 & 0 & \bar{A}_{j-2} & \bar{B}_{j-2}-\bar{A}_{j-2} & \bar{C}_{j-2} & \bar{D}_{j-2}
\end{array}\right]\left[\begin{array}{c}
F_{j} \\
F_{j-1} \\
F_{j-2} \\
F_{j-3} \\
z_{j-3} \\
\dot{z}_{j-3}
\end{array}\right]
$$$$
=\mathbf{H}_{j-2}\left[\begin{array}{c}
F_{j} \\
F_{j-1} \\
F_{j-2} \\
F_{j-3} \\
z_{j-3} \\
\dot{z}_{j-3}
\end{array}\right]
$$$$
\left[\begin{array}{c}
F_{j} \\
F_{j-1} \\
\vdots \\
F_{1} \\
z_{1} \\
\dot{z}_{1}
\end{array}\right]=\left[\begin{array}{ccccccc}
1 & 0 & \cdots & 0 & 0 & 0 & 0 \\
0 & 1 & \cdots & 0 & 0 & 0 & 0 \\
\vdots & \vdots & \ddots & 0 & 0 & 0 & 0 \\
0 & 0 & 0 & 1 & 0 & 0 & 0 \\
0 & 0 & 0 & A_{1} & B_{1}-A_{1} & B_{1} & D_{1} \\
0 & 0 & 0 & \bar{A}_{1} & \bar{B}_{1}-\bar{A}_{1} & \bar{B}_{1} & \bar{D}_{1}
\end{array}\right]\left[\begin{array}{c}
F_{j} \\
F_{j-1} \\
\vdots \\
F_{1} \\
F_{0} \\
z_{0} \\
\dot{z}_{0}
\end{array}\right]
$$$$
=\mathbf{H}_{1}\left[\begin{array}{c}
F_{j} \\
F_{j-1} \\
\vdots \\
F_{1} \\
F_{0} \\
z_{0} \\
\dot{z}_{0}
\end{array}\right] .
$$

$$
\left[\begin{array}{c}
F_{j} \\
F_{j-1} \\
z_{j-1} \\
\dot{z}_{j-1}
\end{array}\right]=\mathbf{H}_{j-1}, \mathbf{H}_{j-2}, \ldots, \mathbf{H}_{1}\left[\begin{array}{c}
F_{j} \\
F_{j-1} \\
\vdots \\
F_{1} \\
F_{0} \\
z_{0} \\
\dot{z}_{0}
\end{array}\right] .
$$

Let $\quad \mathbf{H}^{*}=\left[\begin{array}{cccc}A_{j} & B_{j}-A_{j} & C_{j} & D_{j} \\ \bar{A}_{j} & \bar{B}_{j}-\bar{A}_{j} & \bar{C}_{j} & \bar{D}_{j}\end{array}\right], \quad \mathbf{H}=\mathbf{H}^{*} \prod_{k=1}^{j-1} \mathbf{H}_{k}$, $\mathbf{F}=\left[\begin{array}{lllll}F_{j} & F_{j-1} & \cdots & F_{1} & F_{0}\end{array}\right]^{\mathrm{T}}$, and $\mathbf{z}_{0}=\left[\begin{array}{ll}z_{0} & \dot{z}_{0}\end{array}\right]^{\mathrm{T}}$, then Equation (12) can be expressed as

$$
\left[\begin{array}{c}
z_{j} \\
\dot{z}_{j}
\end{array}\right]=\mathbf{H}\left[\begin{array}{c}
\mathbf{F} \\
\mathbf{z}_{0}
\end{array}\right]
$$

where $\mathbf{H}$ is a $2 \times(j+3)$ constant coefficient matrix, $\mathbf{F}$ is the vector of force sequence, and $\mathbf{z}_{0}$ is the initial condition.

2.2.2. Under Uncertain Excitation. In nonrandom vibration analysis of the interval process model, the external excitation is treated as an interval process, $F^{\mathrm{I}}(t)=\left[F^{\mathrm{L}}(t), F^{\mathrm{U}}(t)\right]$, and the autocorrelation function is $r\left(t_{i}, t_{j}\right) . F^{\mathrm{I}}(t)$ can be represented by an interval vector, $F^{I}=$ $\left[\begin{array}{lllll}F_{j}^{\mathrm{I}} & F_{j-1}^{\mathrm{I}} & \cdots & F_{1}^{\mathrm{I}} & F_{0}^{\mathrm{I}}\end{array}\right]^{\mathrm{T}}$ (Equation (16)). Therefore, Equation (15) can be rewritten by eliminating correlation between variables and transforming them into an independent interval processes $\bar{F}^{\mathrm{I}}(t)$ :

$$
\left[\begin{array}{c}
z_{j} \\
\dot{z}_{j}
\end{array}\right]=\mathbf{H}\left[\begin{array}{l}
\mathbf{F}^{\mathbf{I}} \\
\mathbf{z}_{0}
\end{array}\right] \text {. }
$$

$F^{\mathrm{I}}(t)$ is obtained through Cholesky decomposition, by eliminating the correlation between variables and transforming them into independent interval processes, $\bar{F}^{\mathrm{I}}(t)$, with a corresponding interval vector, $\bar{F}^{\mathrm{I}}$. The following equation can be obtained [23]:

$$
\overline{\mathbf{F}}^{\mathbf{I}}=\mathbf{L}^{-1} \mathbf{F}^{\mathbf{I}}
$$

The corresponding interval middle point vector is $\bar{F}^{\mathrm{C}}$, for which the following equation can be obtained:

$$
\overline{\mathbf{F}}^{\mathrm{C}}=\mathbf{L}^{-1} \mathbf{F}^{\mathrm{C}} \text {. }
$$

The following equation can be obtained for the corresponding interval half width vector $\bar{F}^{\mathrm{W}}$ :

$$
\overline{\mathbf{F}}^{\mathrm{W}}=[|\mathbf{L}|]^{-1} \mathbf{F}^{\mathrm{W}},
$$

where $\mathbf{L}$ is a $(j+1) \times(j+1)$ lower triangular matrix, $[|\mathbf{L}|]$ denotes the matrix whose entries are absolute values of corresponding ones in the matrix L.Through this treatment, Equation (16) can be rewritten as [23]:

$$
\left[\begin{array}{c}
z_{j} \\
\dot{z}_{j}
\end{array}\right]=\mathbf{H}\left[\begin{array}{c}
\mathbf{L} \overline{\mathbf{F}}^{\mathrm{I}} \\
\mathbf{z}_{0}
\end{array}\right]=\left[\begin{array}{ll}
\mathbf{H}_{\mathbf{F}} & \mathbf{H}_{\mathbf{Z}}
\end{array}\right]\left[\begin{array}{c}
\mathbf{L} \overline{\mathbf{F}}^{\mathrm{I}} \\
\mathbf{z}_{0}
\end{array}\right]=\mathbf{H}_{\mathbf{F}} \mathbf{L} \overline{\mathbf{F}}^{\mathrm{I}}+\mathbf{H}_{\mathbf{Z}} \mathbf{z}_{0},
$$

Hence, there is: 
where $\mathbf{H}_{\mathrm{F}}$ and $\mathbf{H}_{\mathrm{Z}}$ are block matrices of $\mathbf{H}$, with dimensions $2 \times(j+1)$ and $2 \times 2$, respectively.

Denote $[\boldsymbol{\delta}] \bar{F}^{\mathrm{W}}$ as

$$
\begin{aligned}
{[\boldsymbol{\delta}] \overline{\mathbf{F}}^{\mathrm{W}} } & =\left[\begin{array}{llll}
\delta_{j}^{\mathrm{I}} \overline{\mathbf{F}}_{j}^{\mathrm{W}} & \cdots & \delta_{1}^{\mathrm{I}} \overline{\mathbf{F}}_{1}^{\mathrm{W}} & \delta_{0}^{\mathrm{I}} \overline{\mathbf{F}}_{0}^{\mathrm{W}}
\end{array}\right]^{\mathrm{T}}, \\
\delta_{\mathrm{i}}^{\mathrm{I}} & =[-1,1], i=0,1, \ldots, j .
\end{aligned}
$$

Let $\bar{F}^{\mathrm{I}}=\left[\bar{F}^{\mathrm{C}}-\bar{F}^{\mathrm{W}}, \mathrm{F}^{\mathrm{C}}+\bar{F}^{\mathrm{W}}\right]$. According to Equations (18)-(20), $\bar{F}^{\mathrm{I}}$ can be rewritten as

$$
\overline{\mathbf{F}}^{\mathrm{I}}=\overline{\mathbf{F}}^{\mathrm{C}}+[\boldsymbol{\delta}] \overline{\mathbf{F}}^{\mathrm{W}} .
$$

Substituting Equations (22), (18), and (19) in Equation (20) yields

$$
\begin{aligned}
& {\left[\begin{array}{c}
z_{j} \\
\dot{z}_{j}
\end{array}\right]=\mathbf{H}_{\mathbf{F}} \mathbf{L} \overline{\mathbf{F}}^{\mathrm{I}}+\mathbf{H}_{\mathbf{Z}} \mathbf{z}_{0}} \\
& =\mathbf{H}_{\mathrm{F}} \mathbf{L} \overline{\mathbf{F}}^{\mathrm{C}}+\mathbf{H}_{\mathrm{F}} \mathbf{L}[\boldsymbol{\delta}] \overline{\mathbf{F}}^{\mathrm{W}}+\mathbf{H}_{\mathrm{Z}} \mathbf{z}_{0}
\end{aligned}
$$

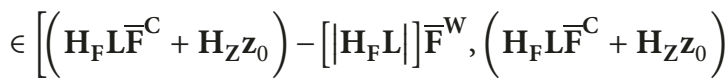

$$
\begin{aligned}
& \left.+\left[\left|\mathbf{H}_{\mathbf{F}} \mathbf{L}\right|\right] \overline{\mathbf{F}}^{\mathrm{W}}\right] \\
& =\left[\left(\mathbf{H}_{\mathbf{F}} \mathbf{L} \mathbf{L}^{-1} \mathbf{F}^{\mathrm{C}}+\mathbf{H}_{\mathbf{Z}} \mathbf{z}_{0}\right)-\left[\left|\mathbf{H}_{\mathbf{F}} \mathbf{L}\right|\right][|\mathbf{L}|]^{-1} \mathbf{F}^{\mathbf{W}},\right. \\
& \left.\left(\mathbf{H}_{\mathbf{F}} \mathbf{L} \mathbf{L}^{-1} \mathbf{F}^{\mathrm{C}}+\mathbf{H}_{\mathbf{Z}} \mathbf{z}_{0}\right)-\left[\left|\mathbf{H}_{\mathbf{F}} \mathbf{L}\right|\right][|\mathbf{L}|]^{-1} \mathbf{F}^{\mathrm{W}}\right] \\
& =\left[\left(\mathbf{H}_{\mathbf{F}} \mathbf{F}^{\mathrm{C}}+\mathbf{H}_{\mathbf{Z}} \mathbf{z}_{0}\right)-\left[\left|\mathbf{H}_{\mathbf{F}} \mathbf{L}\right|\right][|\mathbf{L}|]^{-1} \mathbf{F}^{\mathrm{W}},\right. \\
& \left.\left(\mathbf{H}_{\mathrm{F}} \mathbf{F}^{\mathrm{C}}+\mathbf{H}_{\mathbf{Z}} \mathbf{z}_{0}\right)-\left[\left|\mathbf{H}_{\mathrm{F}} \mathbf{L}\right|\right][|\mathbf{L}|]^{-1} \mathbf{F}^{\mathrm{W}}\right] .
\end{aligned}
$$

This implies that the upper and lower bounds of the displacement response at time $t=t_{j}$ are

$$
\begin{aligned}
& z_{j}^{\mathrm{U}}=\left(\left(\mathbf{H}_{\mathbf{F}}\right)_{1} \mathbf{F}^{\mathrm{C}}+\left(\mathbf{H}_{\mathbf{Z}}\right)_{1} \mathbf{z}_{0}\right)+\left[\left|\left(\mathbf{H}_{\mathbf{F}}\right)_{1} \mathbf{L}\right|\right][|\mathbf{L}|]^{-1} \mathbf{F}^{\mathrm{W}}, \\
& z_{j}^{\mathrm{L}}=\left(\left(\mathbf{H}_{\mathbf{F}}\right)_{1} \mathbf{F}^{\mathrm{C}}+\left(\mathbf{H}_{\mathbf{Z}}\right)_{1} \mathbf{z}_{0}\right)-\left[\left|\left(\mathbf{H}_{\mathbf{F}}\right)_{1} \mathbf{L}\right|\right][|\mathbf{L}|]^{-1} \mathbf{F}^{\mathrm{W}} .
\end{aligned}
$$

Similarly, the upper and lower bounds of velocity response at time $t=t_{j}$ can be obtained as

$$
\begin{aligned}
& \dot{z}_{j}^{\mathrm{U}}=\left(\left(\mathbf{H}_{\mathrm{F}}\right)_{2} \mathbf{F}^{\mathrm{C}}+\left(\mathbf{H}_{\mathbf{Z}}\right)_{2} \mathbf{z}_{0}\right)+\left[\left|\left(\mathbf{H}_{\mathrm{F}}\right)_{2} \mathbf{L}\right|\right][|\mathbf{L}|]^{-1} \mathbf{F}^{\mathrm{W}}, \\
& \dot{z}_{j}^{\mathrm{L}}=\left(\left(\mathbf{H}_{\mathbf{F}}\right)_{2} \mathbf{F}^{\mathrm{C}}+\left(\mathbf{H}_{\mathbf{Z}}\right)_{2} \mathbf{z}_{0}\right)-\left[\left|\left(\mathbf{H}_{\mathbf{F}}\right)_{2} \mathbf{L}\right|\right][|\mathbf{L}|]^{-1} \mathbf{F}^{\mathrm{W}}
\end{aligned}
$$

Equation (5) can be rewritten as

$$
\ddot{z}_{j}=-\frac{c}{m} \dot{z}_{j}-\frac{k}{m} z_{j}+\frac{F(t)}{m} .
$$

Also

$$
\dot{z}_{j}=\dot{z}_{j}
$$

Rewrite Equations (26) and (27) in matrix form:

$$
\left[\begin{array}{c}
\dot{z}_{j} \\
\ddot{z}_{j}
\end{array}\right]=\left[\begin{array}{cc}
0 & 1 \\
-\frac{k}{m} & -\frac{c}{m}
\end{array}\right]\left[\begin{array}{c}
z_{j} \\
\dot{z}_{j}
\end{array}\right]+\left[\begin{array}{c}
0 \\
\frac{1}{m}
\end{array}\right] F(t) .
$$

From $z_{j} \in\left[z_{j}^{\mathrm{L}}, z_{j}^{\mathrm{U}}\right]=z_{j}^{\mathrm{I}}, \dot{z}_{j} \in\left[\dot{z}_{j}^{\mathrm{L}}, \dot{z}_{j}^{\mathrm{U}}\right]=\dot{z}_{j}^{\mathrm{I}}, \ddot{z}_{j} \in\left[\ddot{z}_{j}^{\mathrm{L}}, \ddot{z}_{j}^{\mathrm{U}}\right]=$ $\ddot{z}_{j}^{\mathrm{I}}, F(t) \in\left[F^{\mathrm{L}}(t), F^{\mathrm{U}^{\mathrm{j}}}(t)\right]=F^{\mathrm{I}}(t)$, where $z_{j}^{\mathrm{I}}$, $\dot{z}_{j}^{\mathrm{I}}$ and $\ddot{z}_{j}^{\mathrm{I}}$ are the interval displacement response, interval velocity response, and interval acceleration response, respectively.

Equation (28a) can be rewritten as

$$
\left[\begin{array}{c}
\dot{z}_{j}^{\mathrm{I}} \\
\ddot{z}_{j}^{\mathrm{I}}
\end{array}\right]=\left[\begin{array}{cc}
0 & 1 \\
-\frac{k}{m} & -\frac{c}{m}
\end{array}\right]\left[\begin{array}{c}
z_{j}^{\mathrm{I}} \\
\dot{z}_{j}^{\mathrm{I}}
\end{array}\right]+\left[\begin{array}{c}
0 \\
\frac{1}{m}
\end{array}\right] F^{\mathrm{I}}(t) .
$$

Equation (26) indicates that the upper and lower bounds of acceleration response can be obtained as

$$
\begin{gathered}
\ddot{z}_{j}^{\mathrm{L}}=-\frac{c}{m} \dot{z}_{j}^{\mathrm{U}}-\frac{k}{m} z_{j}^{\mathrm{U}}+\frac{F^{\mathrm{L}}(t)}{m}, \\
\ddot{z}_{j}^{\mathrm{U}}=\frac{c}{m} \dot{z}_{j}^{\mathrm{L}}-\frac{k}{m} z_{j}^{\mathrm{L}}+\frac{F^{\mathrm{U}}(t)}{m},
\end{gathered}
$$

where $F^{\mathrm{U}}(t)$ is the upper bound of excitation force and $F^{\mathrm{L}}(t)$ is the lower bound of excitation force.

\section{Data Process Method for HFFB Wind Tunnel Test}

In the wind tunnel test, the mean wind speed profile is adjusted to match the target wind profile as

$$
v=v_{z}\left(\frac{10}{z}\right)^{\alpha},
$$

where $v_{z}$ is the mean wind speed at height $z$ and $\alpha$ is the terrain roughness exponent.

A wind tunnel test is a kind of experiment that uses reduced-scale models to represent the geometrical characteristics of a real building. Based on the principle of similitude, the measured wind forces and moments at the base of the building model can be transformed to the actual wind force acting on the building prototype. To establish the time, geometry, and wind speed similarity relationship between the model and the prototype, time scale ratio $\lambda_{\mathrm{T}}$, geometrical scale ratio $\lambda_{\mathrm{L}}$, and wind speed scale ratio $\lambda_{\mathrm{V}}$ are defined as Equations (31a)-(31c), respectively:

$$
\begin{aligned}
& \lambda_{\mathrm{T}}=\frac{T_{\mathrm{m}}}{T_{\text {full }}}, \\
& \lambda_{\mathrm{L}}=\frac{L_{\mathrm{m}}}{L_{\text {full }}},
\end{aligned}
$$

$$
\lambda_{\mathrm{V}}=\frac{V_{\mathrm{m}}}{V_{\text {full }}},
$$


where $T_{\mathrm{m}}, L_{\mathrm{m}}$, and $V_{\mathrm{m}}$ are the time, geometrical size, and wind speed for the model, respectively. $T_{\text {full }}, L_{\text {full }}$, and $V_{\text {full }}$ are time, geometrical size, and wind speed for actual buildings, respectively.

According to the principle of similitude, the above three satisfies

$$
\frac{T_{\mathrm{m}}}{T_{\text {full }}}=\frac{(L / V)_{\mathrm{m}}}{(L / V)_{\text {full }}}=\frac{L_{\mathrm{m}} / L_{\text {full }}}{V_{\mathrm{m}} / V_{\text {full }}}=\frac{\lambda_{\mathrm{L}}}{\lambda_{\mathrm{V}}} .
$$

Since $T=1 / f$, the scale ratio $T$ of frequency can be obtained as

$$
\frac{f_{\mathrm{m}}}{f_{\text {full }}}=\frac{1}{T_{\mathrm{m}} / T_{\text {full }}}=\frac{1}{\lambda_{T}},
$$

where $f_{\mathrm{m}}$ and $f_{\text {full }}$ are the frequencies for the model and actual building, respectively.

In conventional data analysis of a wind tunnel test, time or frequency scale is a constant for a certain wind direction; however, if a real wind field is nonstationary, the time scale is time-variant. In this study, the entire considered time is separated into a series of time segments defined as $\Delta t_{(i)}$, which can be formulated as

$$
\Delta t_{(i)}=\frac{1}{f_{\text {full }}}=\frac{V_{\mathrm{m}} L_{\text {full }}}{f_{\mathrm{m}} L_{\mathrm{m}}} \frac{1}{V_{\text {full }(i)}}, \quad i=1,2, \ldots, n .
$$

Conventionally, aerodynamic force and moment coefficients are employed to implement the model-toprototype transform. The torque coefficients $\mu_{x}, \mu_{y}$, and $\mu_{z}$ are defined as

$$
\begin{aligned}
& \mu_{x}=\frac{m_{x}}{0.5 \rho V_{\mathrm{h}}^{2} B_{\mathrm{m}} H_{\mathrm{m}}^{2}}, \\
& \mu_{y}=\frac{m_{y}}{0.5 \rho V_{\mathrm{h}}^{2} B_{\mathrm{m}} H_{\mathrm{m}}^{2}}, \\
& \mu_{z}=\frac{m_{z}}{0.5 \rho V_{\mathrm{h}}^{2} B_{\mathrm{m}}^{2} H_{\mathrm{m}}},
\end{aligned}
$$

where $m_{x}, m_{y}$, and $m_{z}$ are the base bending moments measured in the direction $x, y$, and $z$, respectively, $\rho$ is the air density, $V_{\mathrm{h}}$ is the mean wind speed at the model reference height, $B_{\mathrm{m}}$ is the model characteristic width, and $H_{\mathrm{m}}$ is the total height of the model. Through the torque coefficients $\mu_{x}, \mu_{y}$, and $\mu_{z}$, the lower and upper bounds of the base moment of the real building can be formulated as

$$
\begin{aligned}
& M_{\mathrm{L} x}=0.5 \rho V_{\mathrm{L}}^{2} B_{\text {full }} H_{\text {full }}^{2} \mu_{x}, \\
& M_{\mathrm{U} x}=0.5 \rho V_{\mathrm{U}}^{2} B_{\text {full }} H_{\text {full }}^{2} \mu_{x}, \\
& M_{\mathrm{L} y}=0.5 \rho V_{\mathrm{L}}^{2} B_{\text {full }} H_{\text {full }}^{2} \mu_{y}, \\
& M_{\mathrm{U} y}=0.5 \rho V_{\mathrm{U}}^{2} B_{\text {full }} H_{\text {full }}^{2} \mu_{y}, \\
& M_{\mathrm{L} z}=0.5 \rho V_{\mathrm{L}}^{2} B_{\text {full }}^{2} H_{\text {full }} \mu_{z}, \\
& M_{\mathrm{U} z}=0.5 \rho V_{\mathrm{U}}^{2} B_{\text {full }}^{2} H_{\text {full }} \mu_{z},
\end{aligned}
$$

where $M_{\mathrm{U} x}, M_{\mathrm{U} y}$, and $M_{\mathrm{U} z}$ are the upper bounds of the base bending moments of the actual structure in $x, y$, and $z$ direction, respectively; $M_{\mathrm{L} x}, M_{\mathrm{L} y}$, and $M_{\mathrm{L} z}$ are the corresponding lower bounds; $V_{\mathrm{U}}$ and $V_{\mathrm{L}}$ are the upper and lower bounds of the time-variant wind speed; and $B_{\text {full }}$ and $H_{\text {full }}$ are the characteristic width and total height of the real buildings, respectively.

A high-rise building can be examined using a cantilever structure response analysis which satisfies the motional equation as

$$
m(z) \frac{\partial^{2} y}{\partial t^{2}}+c(z) \frac{\partial y}{\partial t}+\frac{\partial^{2}}{\partial z^{2}}\left[\operatorname{EI}(z) \frac{\partial^{2} y}{\partial z^{2}}\right]=p(z, t)
$$

where $m(z), c(z)$, and $\operatorname{EI}(z)$ are the mass, damping coefficient, and flexural rigidity per unit length at height $z$, respectively, and $p(z, t)$ is the horizontal wind load at height $z$ and time instant $t$.

The modal mass $m_{\mathrm{p}}$, modal stiffness $k_{\mathrm{p}}$, and modal damping coefficient $c_{\mathrm{p}}$ for the first mode can be computed as follows:

$$
\begin{aligned}
m_{\mathrm{p}} & =\int_{0}^{H} m(z) \varphi^{2}(z) d z=\frac{1}{H^{2}} \int_{0}^{H} z^{2} m(z) d z, \\
k_{\mathrm{p}} & =\frac{1}{H^{2}} \int_{0}^{H} E I(z) z^{2} d z=\omega_{0}^{2} m_{\mathrm{p}}, \\
c_{\mathrm{p}} & =2 \zeta \omega_{0} m_{\mathrm{p}} .
\end{aligned}
$$

Then, the structural dynamic equation in modal coordinates can be formulated as

$$
m_{\mathrm{p}} \ddot{q}+c_{\mathrm{p}} \dot{q}+k_{\mathrm{p}} q=F(t) .
$$

Assuming the modal shape for the first two sway modes to be linear with height, modal force can be expressed as

$$
F(t)=\int_{0}^{H} \varphi(z) p(z, t) d z=\frac{1}{H} \int_{0}^{H} z p(z, t) d z=\frac{M^{\mathrm{I}}(t)}{H},
$$

where $M^{\mathrm{I}}(t)$ is the base bending moment, which can be measured by the HFFB wind tunnel test.

The whole procedure of the proposed method for estimation of boundary response of high-rise buildings subjected to nonstationary wind load is listed below:

(1) Get the upper and lower bounds of the reference wind speed conventionally from meteorological agencies.

(2) Measure the base forces and torques through a wind tunnel test.

(3) Using the base overturning moments, compute the base overturning moment coefficient according to Equations (35a)-(35c).

(4) Using Equations (36a)-(36c), compute the upper and lower bounds of structural modal force by the following equations: 


$$
\begin{aligned}
& F_{x}^{\mathrm{L}}=\frac{0.5 \rho V_{\mathrm{L}}^{2} B_{\text {full }} H_{\text {full }}^{2} \mu_{x}}{H_{\text {full }}}, \\
& F_{x}^{\mathrm{U}}=\frac{0.5 \rho V_{\mathrm{U}}^{2} B_{\text {full }} H_{\text {full }}^{2} \mu_{x}}{H_{\text {full }}}, \\
& F_{y}^{\mathrm{L}}=\frac{0.5 \rho V_{\mathrm{L}}^{2} B_{\text {full }} H_{\text {full }}^{2} \mu_{y}}{H_{\text {full }}}, \\
& F_{y}^{\mathrm{U}}=\frac{0.5 \rho V_{\mathrm{U}}^{2} B_{\text {full }} H_{\text {full }}^{2} \mu_{y}}{H_{\text {full }}}, \\
& F_{z}^{\mathrm{L}}=\frac{0.5 \rho V_{\mathrm{L}}^{2} B_{\text {full }}^{2} H_{\text {full }} \mu_{z}}{H_{\text {full }}}, \\
& F_{z}^{\mathrm{U}}=\frac{0.5 \rho V_{\mathrm{U}}^{2} B_{\text {full }}^{2} H_{\text {full }} \mu_{z}}{H_{\text {full }}},
\end{aligned}
$$

where $F_{x}^{\mathrm{U}}, F_{y}^{\mathrm{U}}$, and $F_{z}^{\mathrm{U}}$ are the upper bounds of the modal force of the actual structure in the $x, y$, and $z$ directions, respectively, and $F_{x}^{\mathrm{L}}, F_{y}^{\mathrm{L}}$, and $F_{z}^{\mathrm{L}}$ are the corresponding lower bounds.

(5) Compute upper and lower bounds of structural response using Equations (24a), (24b), (25a), (25b), (29a), and (29b).

\section{Case Study}

In this paper, the feasibility of the interval process model and nonrandom vibration analysis method [23] in practical engineering is explained based on dynamic excitation as a stationary interval process, dynamic excitation as a nonstationary interval process, and the engineering example of GZET.

4.1. $F^{I}(t)$ Stationary. As shown in Figure 1, consider a spring-mass-damping system where the mass $m=1$, damping coefficient $c=0.2$, and spring stiffness $k=1$. Herein, $F(t)$ is treated as a stationary interval process $F^{\mathrm{I}}(t)$, $F(t) \in[10,20]$, where the middle point function is $F^{\mathcal{c}}(t)=$ 15 and half width function is $F^{\mathrm{r}}(t)=5$. The initial condition is $z(0)=\dot{z}(0)=0$. The autocorrelation coefficient function is $r(\tau)$.

The autocorrelation coefficient function is assumed to take the form of $r(\tau)=\mathrm{e}^{-\lambda|\tau|}$. Figures 2-4 show the boundary response of displacement, velocity, and acceleration for the case of $\lambda=0.2$. We find that the response bounds of displacement can be roughly divided into two phases: the transient response stage and the steady-state response stage. Before $30 \mathrm{~s}$, the response bounds exhibit obvious oscillation. This kind of oscillation tends to reduce with time until a steady state can be reached. Figures 5-7 show the stationary interval process autocorrelation coefficient function $r(\tau)=\mathrm{e}^{-\lambda|\tau|}$. Cases with different $\lambda$ values are considered to observe the effect of $\lambda$ on the obtained boundary response. As can be seen from the results, as $\lambda$ increases, the interval of the system's steady response phase will increase, indicating that the self-correlation function of the time-varying force, $F^{\mathrm{I}}(t)$, may have a significant impact on dynamic responses, such as displacement and velocity, when the incentive interval is not changed.

4.2. $F^{I}(t)$ Is Nonstationary. This case also focuses on the damped SDOF system in Figure 1, and the values of relevant parameters are the same as those in Section 4.1. The difference is $F^{\mathrm{I}}(t)$. It is a nonstationary interval process, as shown in Figure 8, where the middle point function is $F^{\mathcal{C}}(t)=16+2 \sin t$ and half width function is $F^{\mathrm{r}}(t)=2+\sin t$. Figures 9-11 show the displacement response, velocity response, and acceleration response of the nonstationary interval process. We find that because $F^{\mathrm{I}}(t)$ exhibits a variation of periodicity, the response also exhibits a variation of periodicity, and the periodicity changes are very similar.

Figures 12-14 show the stationary interval process autocorrelation coefficient function $r(\tau)=\mathrm{e}^{-\lambda|\tau|}$. Cases with different $\lambda$ values are considered to observe the effect of $\lambda$ on the obtained boundary response. As can be seen from the results, as $\lambda$ increases, the interval of the system's steady response phase will increase, indicating that the self-correlation function of the time-varying force, $F^{\mathrm{I}}(t)$, may have a significant impact on dynamic responses, such as displacement and velocity, when the incentive interval is not changed.

4.3. The GZET Case Study. In this section, a supertall building, GZET, is used as an example to show the effectiveness of the proposed method. GZET, which is $530 \mathrm{~m}$ high with 112 stories, is in Guangzhou, China. Currently it is the tallest building in Guangzhou and the second tallest building in South China.

An HFFB wind tunnel test of GZET was carried out in the wind tunnel laboratory of South China University of Technology. The experimental section of the wind tunnel laboratory is $5 \mathrm{~m}$ wide, $3 \mathrm{~m}$ high, and $24 \mathrm{~m}$ long. The wind speed of the test section can be adjusted continuously, and the maximum wind speed can reach $30 \mathrm{~m} / \mathrm{s}$. A rigid model with a geometric length scale of $1: 500$ was made to represent GZET. The model was made of balsa and foam and was mounted on a metal slab which was rigidly connected to an HFFB measurement system. Models of surrounding buildings that might affect the wind's effects on the tested building were also made and mounted on the ground of the wind tunnel to simulate the surrounding conditions, as shown in Figure 15. A Pitot tube was installed at the height of the building model (1.06 $\mathrm{m}$ above ground) to measure the reference wind speed. The wind direction was defined as an angle, $\beta$, from the east along an anticlockwise direction, varying from $0^{\circ}$ to $360^{\circ}$ with an increment angle of $10^{\circ}$. Before the formal HFFB wind tunnel test was carried out, the wind profile in the wind tunnel had been adjusted to match the ESDU's wind profile with the exponential parameter $\alpha=0.22$, as shown in Figure 16. In the wind tunnel test, the sampling frequency is $400 \mathrm{~Hz}$ with a sampling length of 40960. The natural frequency of GZET is 0.128 and $0.132 \mathrm{~Hz}$ 


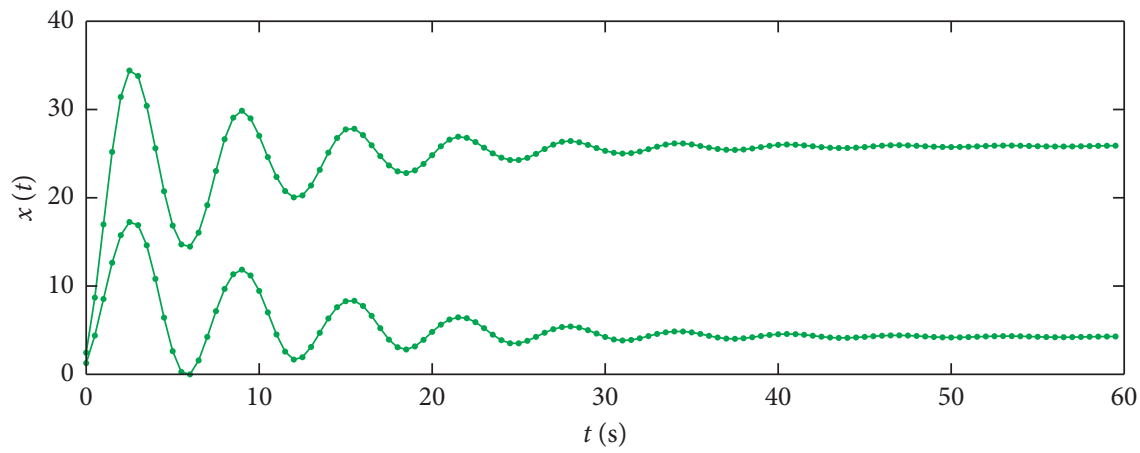

FIGURE 2: Displacement response bounds of a stationary interval process.

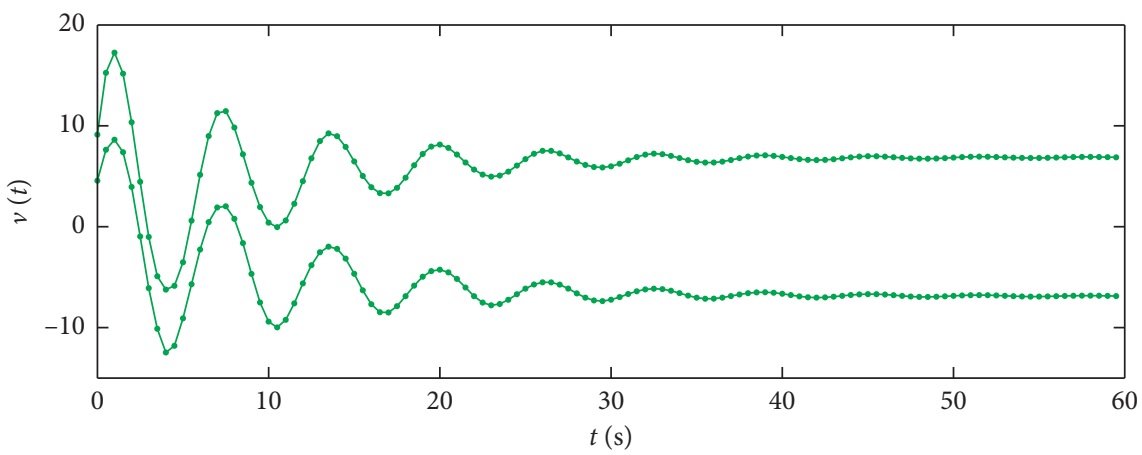

FIGURE 3: Velocity response bounds of a stationary interval process.

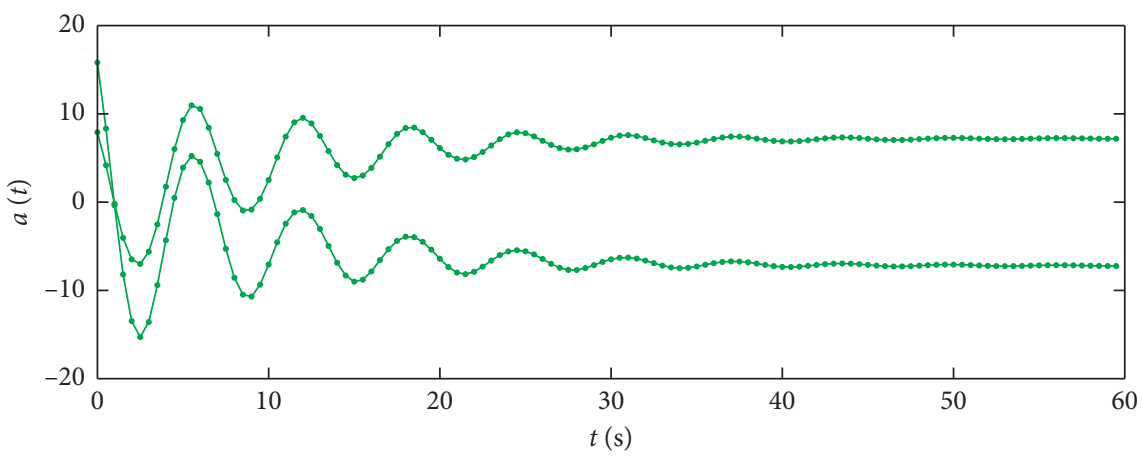

FIgURE 4: Acceleration response bounds of a stationary interval process.

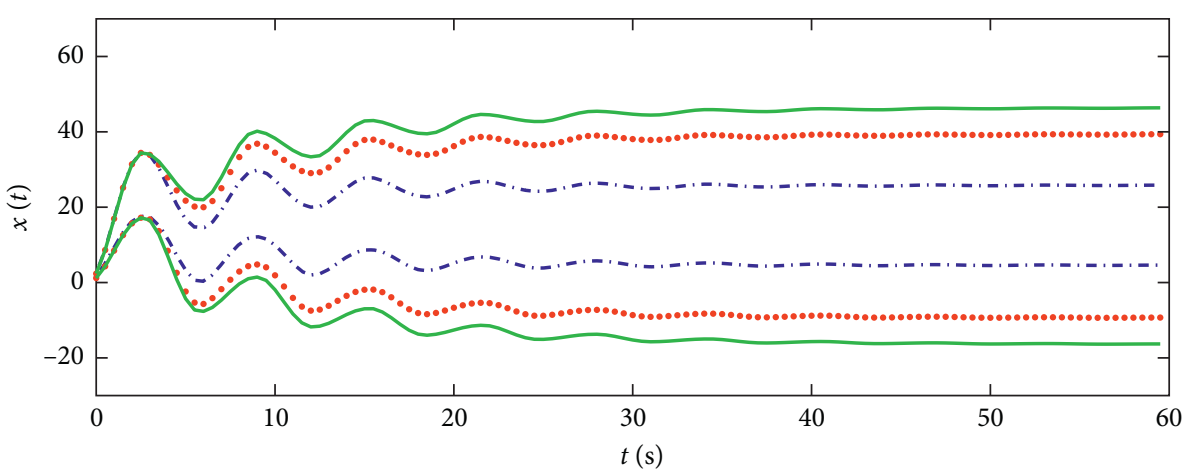

$$
\begin{aligned}
\lambda & =0.2 \\
-\lambda & =1 \\
-\lambda & =10
\end{aligned}
$$

Figure 5: Dynamic displacement response under different values of parameter $\lambda$. 


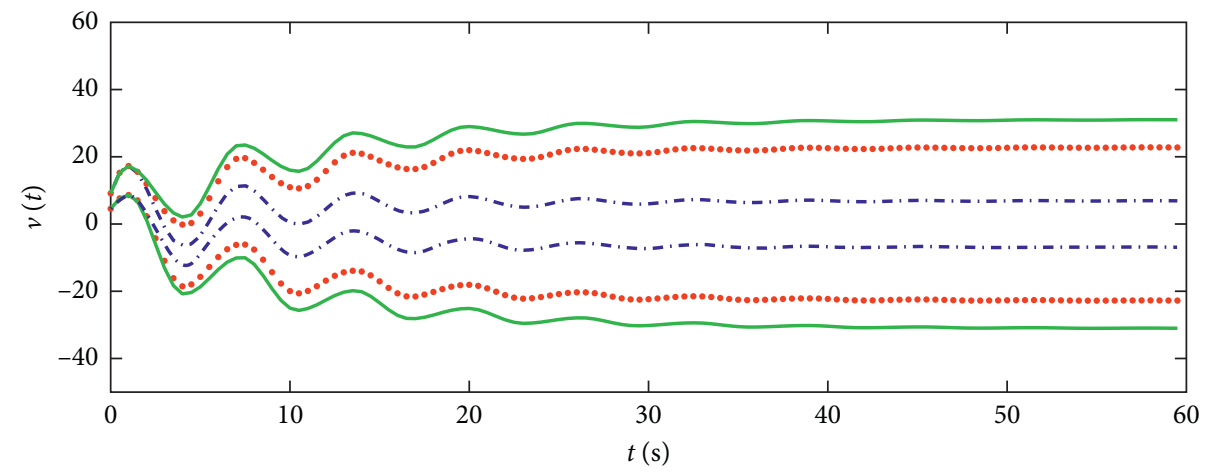

$\begin{aligned} \lambda & =0.2 \\ -\quad \lambda & =5 \\ \lambda & =10\end{aligned}$

FIgURE 6: Dynamic velocity response under different values of parameter $\lambda$.

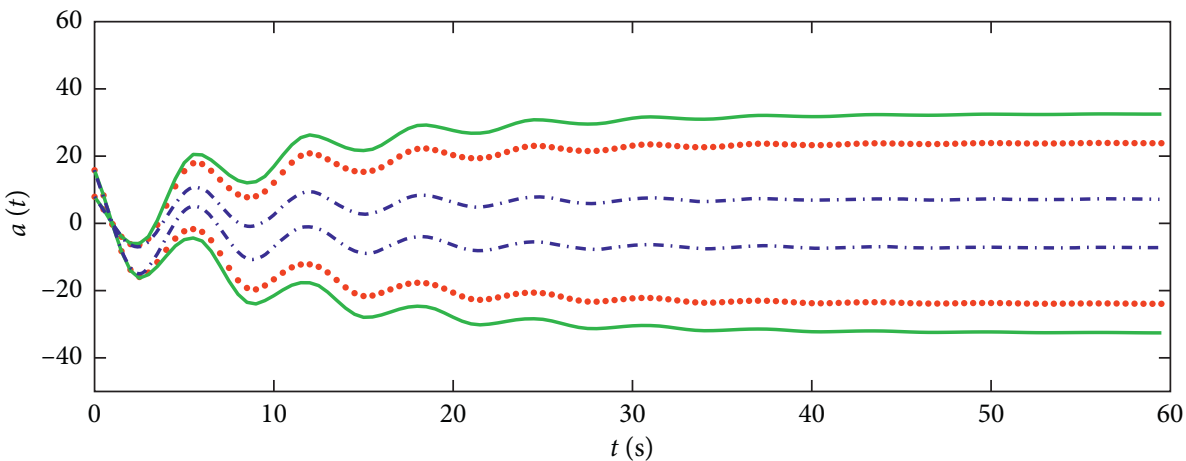

$\begin{aligned} \lambda & =0.2 \\ \lambda & =5\end{aligned}$

$-\lambda=10$

Figure 7: Dynamic acceleration response under different values of parameter $\lambda$.

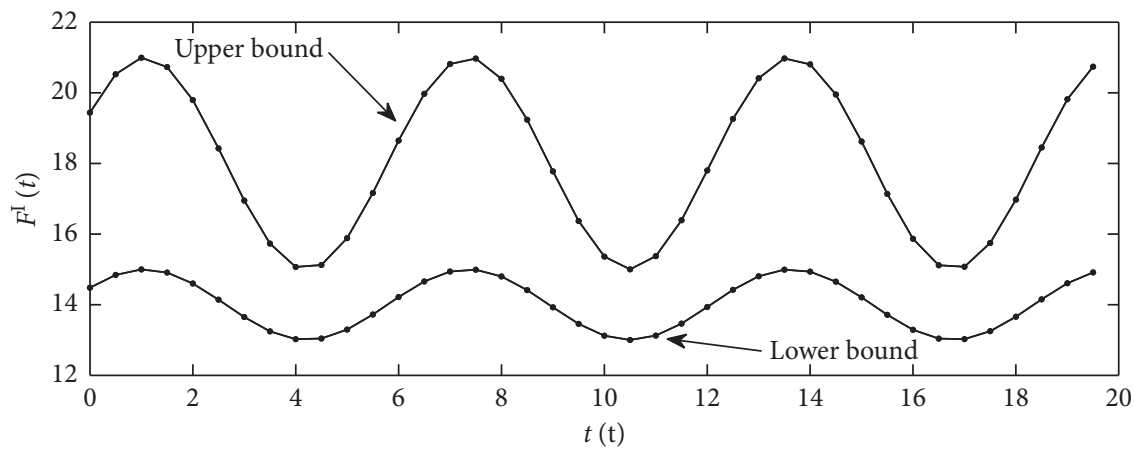

FIgURE 8: The nonstationary excitation force $F^{\mathrm{I}}(t)$.

for the first two sway modes and $0.360 \mathrm{~Hz}$ for the first torsional mode. According to the actual engineering situation, the correlation coefficient function of wind load is obtained directly from wind tunnel test to compute the response boudary of the structure.

In the wind-induced vibration response analysis, using the wind speed of a certain typhoon provided by the meteorological department, 3,600 samples were taken to measure the typhoon wind speed, as shown in Figure 17, and the upper and lower envelope diagrams thereof were plotted according to Figure 17, as shown in Figure 18. Using the upper and lower boundaries of the typhoon wind speed combined with the HFFB wind tunnel test data, structural response boundary values can be obtained. Structural response boundary values are shown in Figures 19-21, which are the displacement, velocity, and 


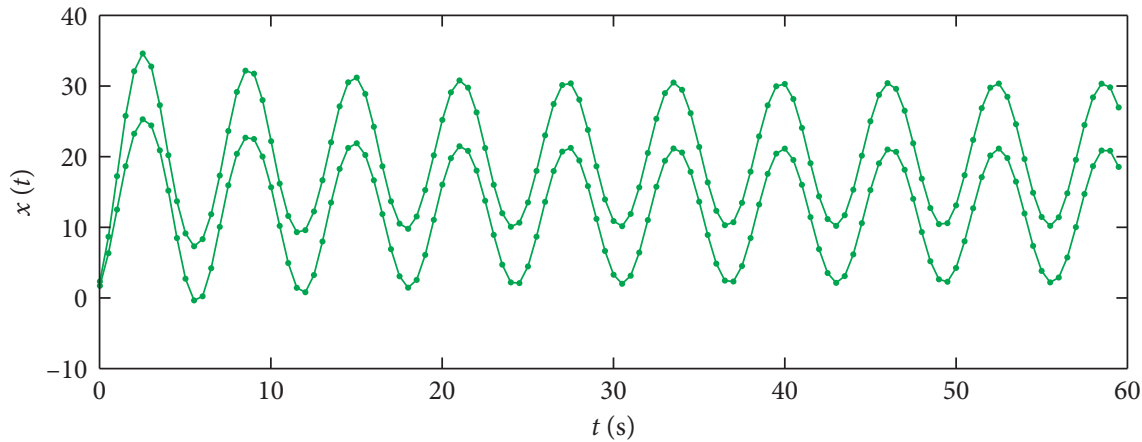

FIGURE 9: Displacement response bounds of a nonstationary interval process.

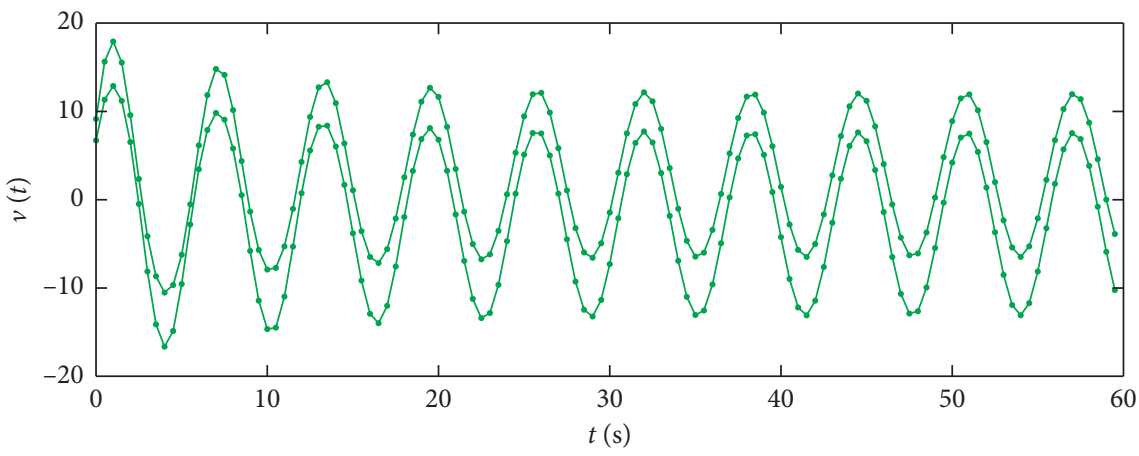

FIGURE 10: Velocity response bounds of a nonstationary interval process.

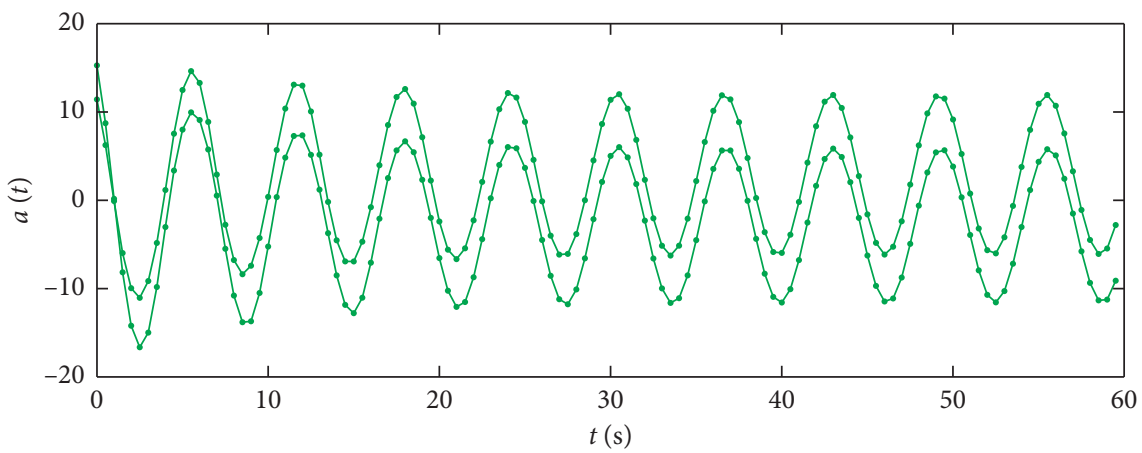

FIgURE 11: Acceleration response bounds of a nonstationary interval process.

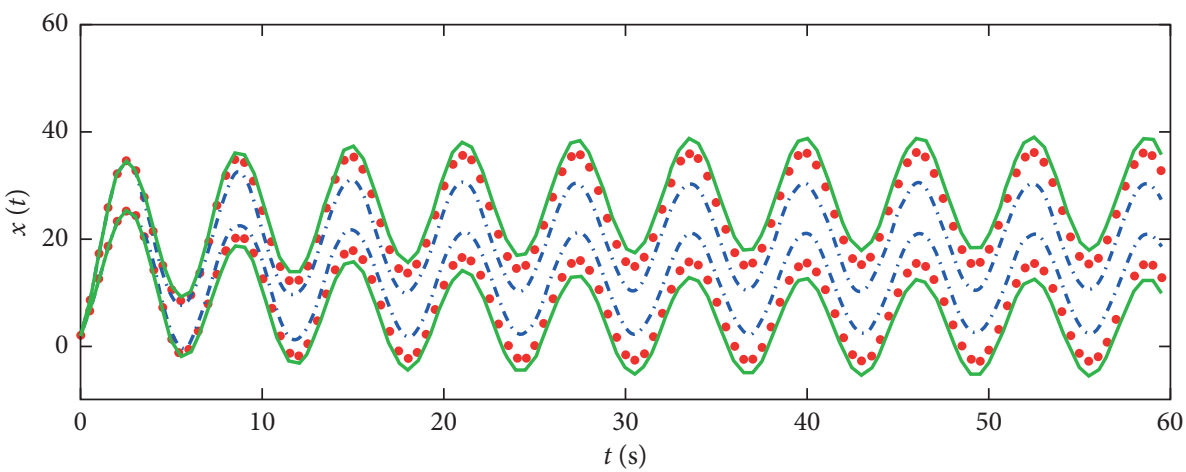

- - $\lambda=0.2$

- $\lambda=1$

$-\lambda=10$

Figure 12: Dynamic displacement response under different values of parameter $\lambda$. 


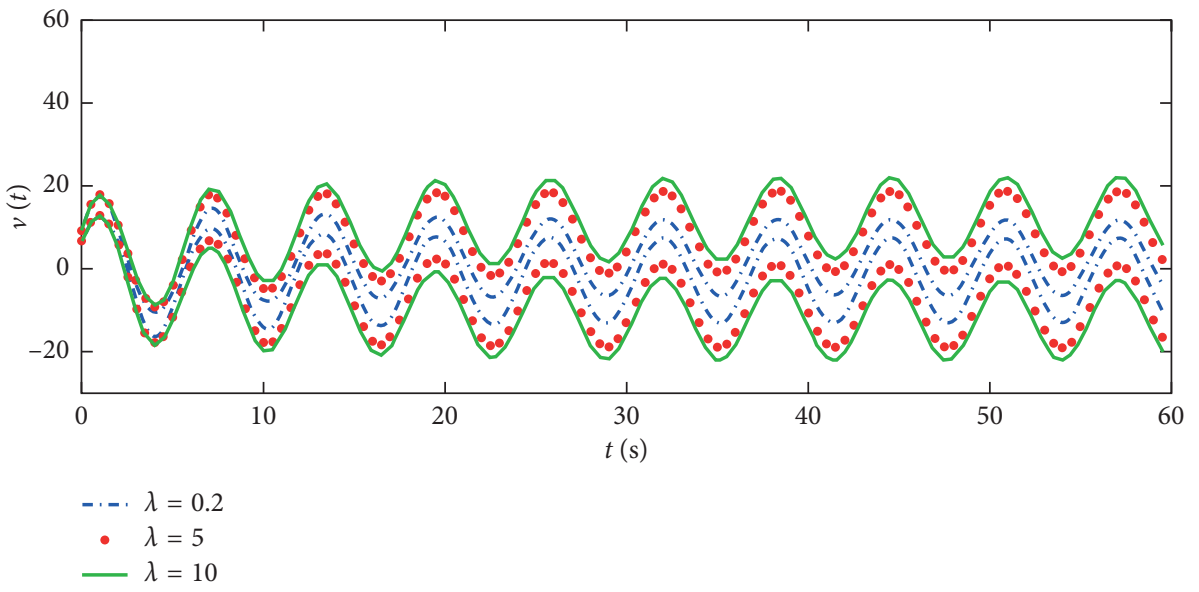

FIgURE 13: Dynamic velocity response under different values of parameter $\lambda$.

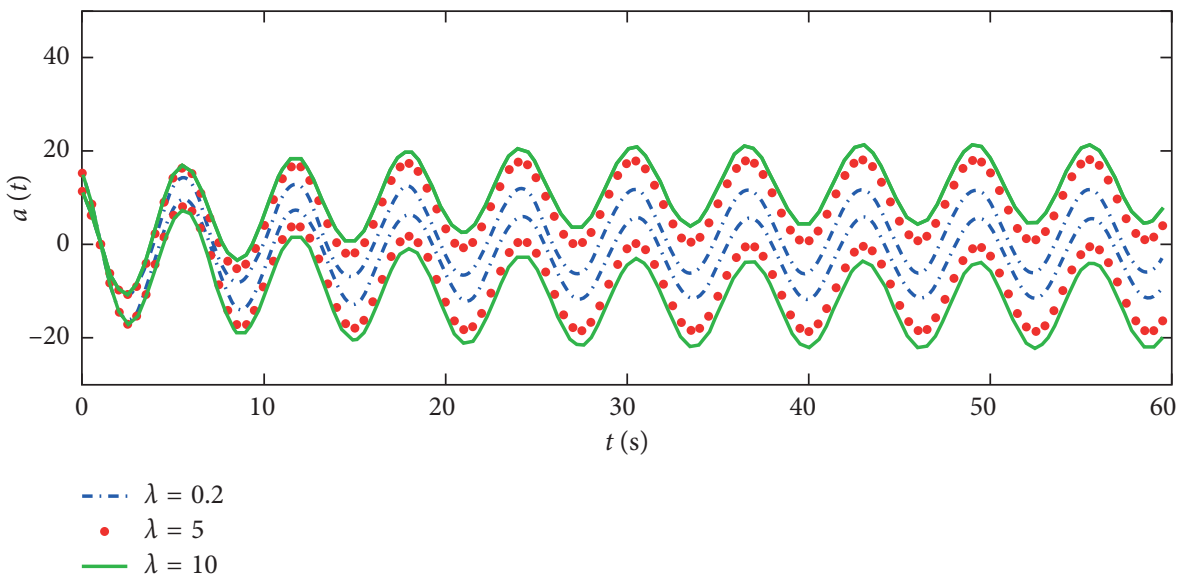

Figure 14: Dynamic acceleration response under different values of parameter $\lambda$.

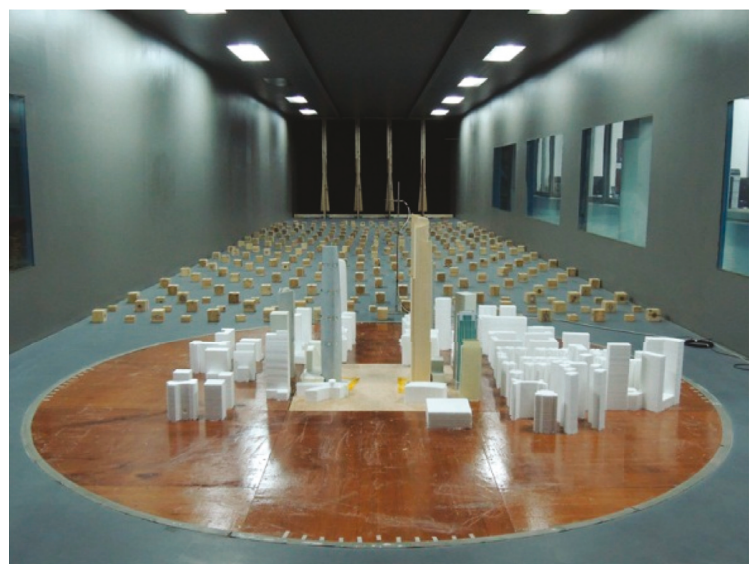

FIGURE 15: Building model of the GZET in the wind tunnel.

acceleration responses of the structure, respectively. To better observe the changing trends of response at each time, the envelopes of structure displacement, velocity, and acceleration responses were, respectively, fitted. In Figures 19-21, the blue curve is the structural boundary response obtained by the interval analysis method, and the red curve is the envelope of the boundary response method which is more intuitive for applications. The envelope diagram can reflect the response at each moment more intuitively and clearly. 


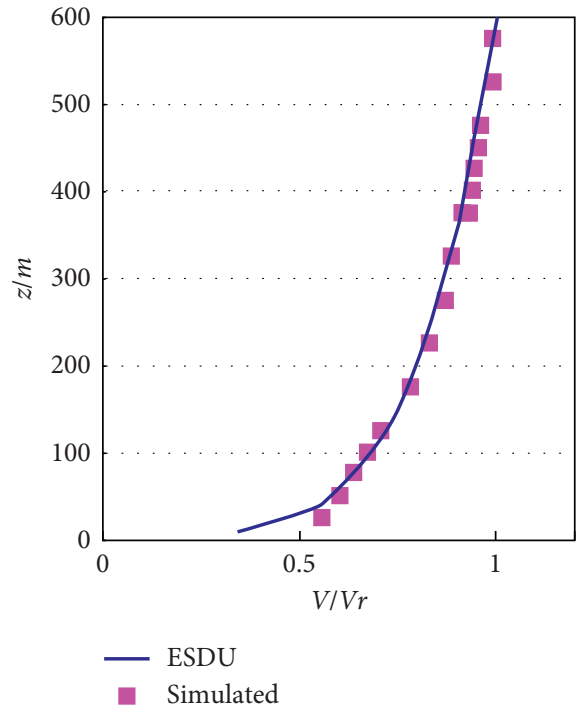

(a)

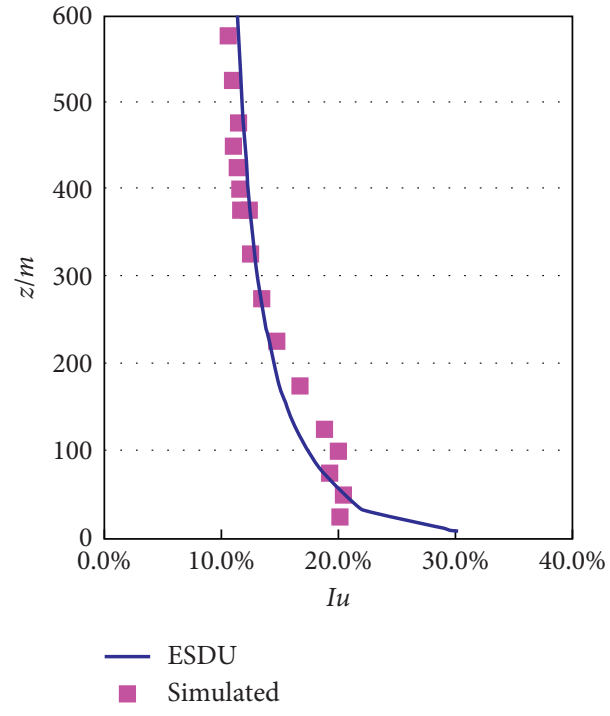

(b)

FIGURE 16: Mean wind speed and turbulence intensity profile. (a) Mean wind speed; (b) turbulence intensity.

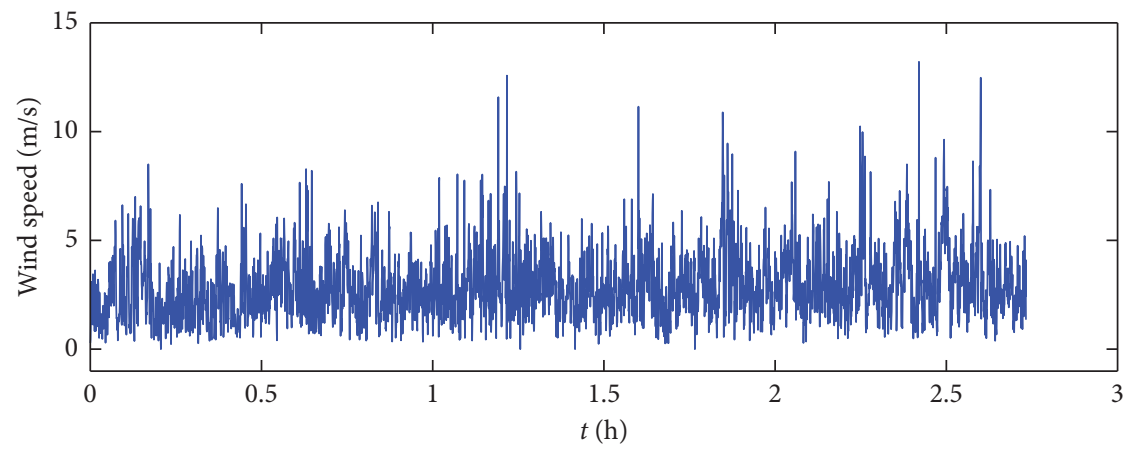

FiguRe 17: Segment of field-measured wind speed.

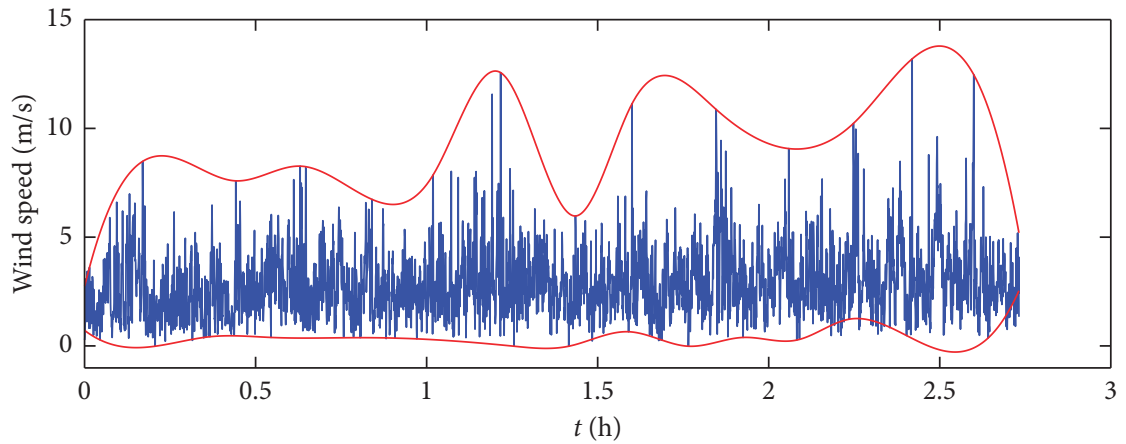

FIGURE 18: Envelope of the wind speed.

\section{Conclusions}

Based on the HFFB technique and interval process model analysis theory, this paper proposes a new method for estimating the response boundary of high-rise building structures based on nonstationary wind loads. With a given nonstationary reference wind speed, this method can provide the upper and lower bounds for displacement, velocity, and acceleration response for different time instants. With the predicted wind information of a typhoon, it is easy to know the possible largest response for different time segments, which helps the owner of a building take necessary measures to prevent a typhoon disaster and reduce damage. This new method will help 


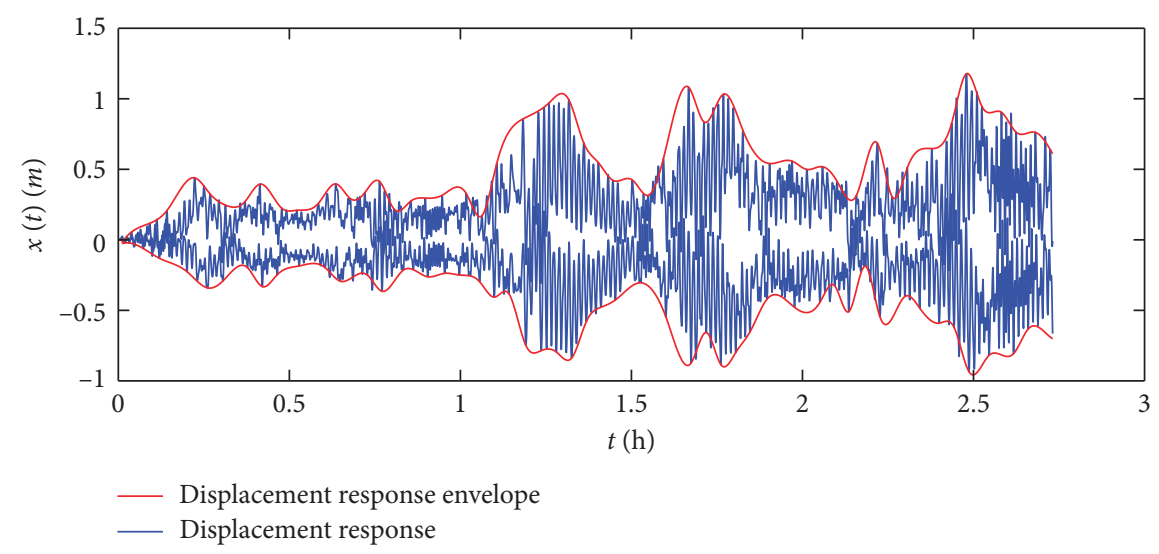

FIGURE 19: Boundary response of displacement atop the building.

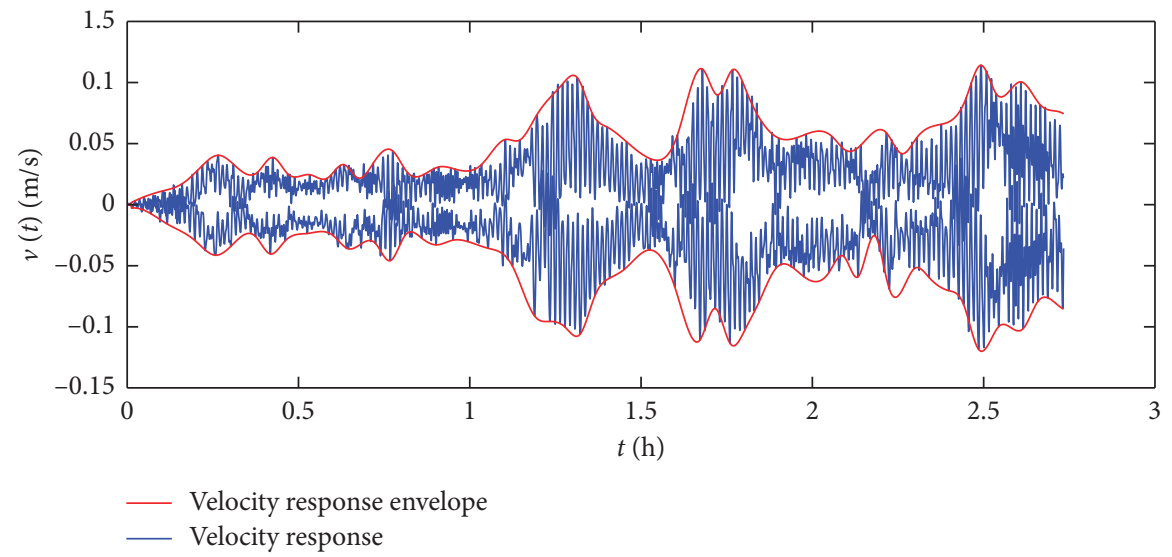

FIGURE 20: Boundary response of velocity atop the building.

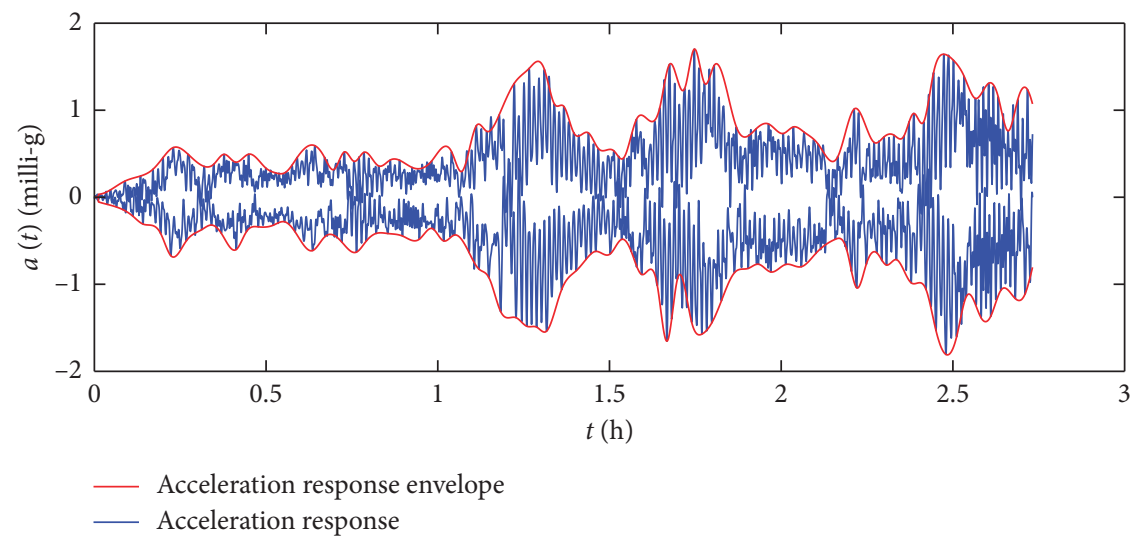

FIGURE 21: Boundary response of acceleration atop the building.

researchers and engineers prevent and control typhoon disasters in high-rise buildings.

\section{Data Availability}

The wind tunnel test data (in $*$.txt files) to support the findings of this study were supplied by Guangzhou University with license and so cannot be made freely available.
Request for access to these data should be made to the corresponding author after publication of this article.

\section{Conflicts of Interest}

The authors declare that there are no conflicts of interest regarding the publication of this paper. 


\section{Acknowledgments}

This work is fully supported by grants from the National Science Foundation of China (51478130), and the China Scholarship Council (201808440070). The financial supports are gratefully acknowledged.

\section{References}

[1] Hirai and Hiroyuki, "Influence of number of experimental wind force samples on wind response analysis of a tall building," AIJ Journal of Technology and Design, vol. 18, no. 39, pp. 489-494, 2012.

[2] A. Xu and Z. N. Xie, "Amplitude dependency of damping of tall structures by the random decrement technique," Wind and Structures, vol. 21, no. 2, pp. 159-182, 2015.

[3] A. Xu, "Evaluation of wind loads on super-tall buildings from field-measured wind-induced acceleration response," Structural Design of Tall and Special Buildings, vol. 23, no. 9, pp. 641-663, 2014.

[4] A. Xu, J. Wu, and R. Zhao, "Wavelet-transform-based damping identification of a super-tall building under strong wind loads," Wind and Structures, vol. 19, no. 4, pp. 353-370, 2014.

[5] A. Xu, Z. N. Xie, and M. Gu, "A new method for dynamic parameters identification of a model-balance system in highfrequency force-balance wind tunnel tests," Journal of Vibroengineering, vol. 17, no. 5, pp. 2609-2623, 2015.

[6] Z. Qiu and I. Elishakoff, "Antioptimization of structures with large uncertain-but-non-random parameters via interval analysis," Computer Methods in Applied Mechanics and Engineering, vol. 152, no. 3-4, pp. 361-372, 1998.

[7] S. Chen, H. Lian, and X. Yang, "Interval static displacement analysis for structures with interval parameters," International Journal for Numerical Methods in Engineering, vol. 53, no. 2, pp. 393-407, 2002.

[8] Z. Qiu and X. Wang, "Parameter perturbation method for dynamic responses of structures with uncertain-but-bounded parameters based on interval analysis," International Journal of Solids and Structures, vol. 42, no. 18-19, pp. 4958-4970, 2005.

[9] D. Moens and D. Vandepitte, "Interval sensitivity theory and its application to frequency response envelope analysis of uncertain structures," Computer Methods in Applied Mechanics and Engineering, vol. 196, no. 21-24, pp. 2486-2496, 2007.

[10] W. Verhaeghe, W. Desmet, D. Vandepitte, and D. Moens, "Interval fields to represent uncertainty on the output side of a static FE analysis," Computer Methods in Applied Mechanics and Engineering, vol. 260, no. 5, pp. 50-62, 2013.

[11] C. Jiang, "Giving dynamic response bounds under uncertain excitations-a non-random vibration analysis method," Chinese Journal of Theoretical and Applied Mechanics, vol. 48, no. 2, pp. 447-463, 2016.

[12] C. Jiang, Z. G. Zhang, and Q. F. Zhang, "A new nonlinear interval programming method for uncertain problems with dependent interval variables," European Journal of Operational Research, vol. 238, no. 1, pp. 245-253, 2014.

[13] W. Gao, C. Song, and F. Tin-Loi, "Probabilistic interval analysis for structures with uncertainty," Structural Safety, vol. 32, no. 3, pp. 191-199, 2010.

[14] L. Wang, C. Xiong, and Y. Yang, "A novel methodology of reliability-based multidisciplinary design optimization under hybrid interval and fuzzy uncertainties," Computer Methods in Applied Mechanics and Engineering, vol. 337, pp. 439-457, 2018.

[15] L. Wang, C. Xiong, and X. J. Wang, "A dimension-wise method and its improvement for multidisciplinary interval uncertainty analysis," Applied Mathematical Modelling, vol. 59, pp. 680-695, 2018.

[16] L. Wang, C. Xiong, X. Wang, Y. Li, and M. Xu, "Hybrid timevariant reliability estimation for active control structures under aleatory and epistemic uncertainties," Journal of Sound and Vibration, vol. 419, pp. 469-492, 2018.

[17] T. Tschanz and A. G. Davenport, "The base balance technique for the determination of dynamic wind loads," Journal of Wind Engineering and Industrial Aerodynamics, vol. 13, no. 1-3, pp. 429-439, 1983.

[18] J. Xie and P. A. Irwin, "Application of the force balance technique to a building complex," Journal of Wind Engineering and Industrial Aerodynamics, vol. 77-78, no. 98, pp. 579-590, 1998.

[19] E. Bernardini, S. M. J. Spence, and A. Kareem, "A probabilistic approach for the full response estimation of tall buildings with 3D modes using the HFFB," Structural Safety, vol. 44, no. 2334, pp. 91-101, 2013.

[20] E. Bernardini, S. M. J. Spence, and M. Gioffrè, "Effects of the aerodynamic uncertainties in HFFB loading schemes on the response of tall buildings with coupled dynamic modes," Engineering Structures, vol. 42, no. 12, pp. 329-341, 2012.

[21] K. M. Lam and A. Li, "Mode shape correction for windinduced dynamic responses of tall buildings using timedomain computation and wind tunnel tests," Journal of Sound and Vibration, vol. 322, no. 4-5, pp. 740-755, 2009.

[22] Z. N. Xie and M. Gu, "Simplified formulas for evaluation of wind-induced interference effects among three tall buildings," Journal of Wind Engineering and Industrial Aerodynamics, vol. 95, no. 1, pp. 31-52, 2007.

[23] C. Jiang, B. Y. Ni, and N. Y. Liu, "Interval process model and non-random vibration analysis," Journal of Sound and Vibration, vol. 373, pp. 104-131, 2016.

[24] B. Hamann and J. L. Chen, "Data point selection for piecewise linear curve approximation," Computer Aided Geometric Design, vol. 11, no. 3, pp. 289-301, 1994. 


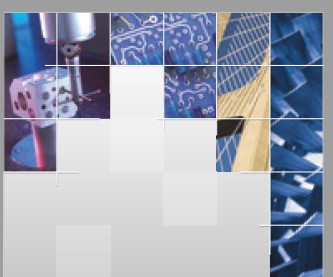

\section{Enfincering}
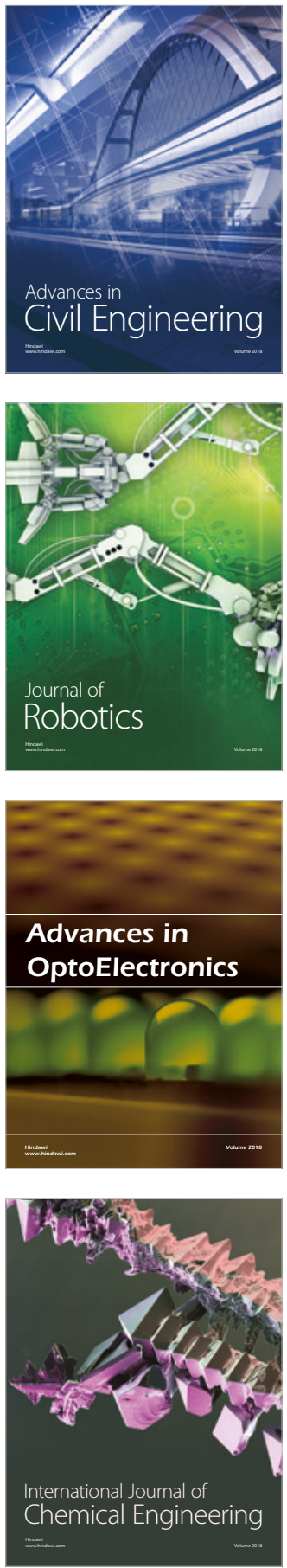

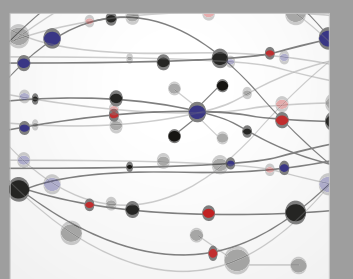

\section{Rotating \\ Machinery}

The Scientific World Journal

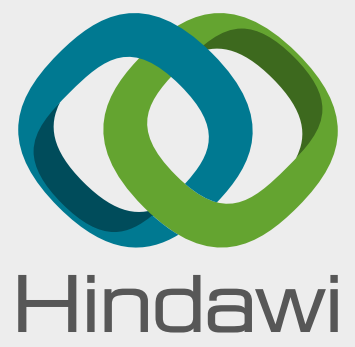

Submit your manuscripts at

www.hindawi.com
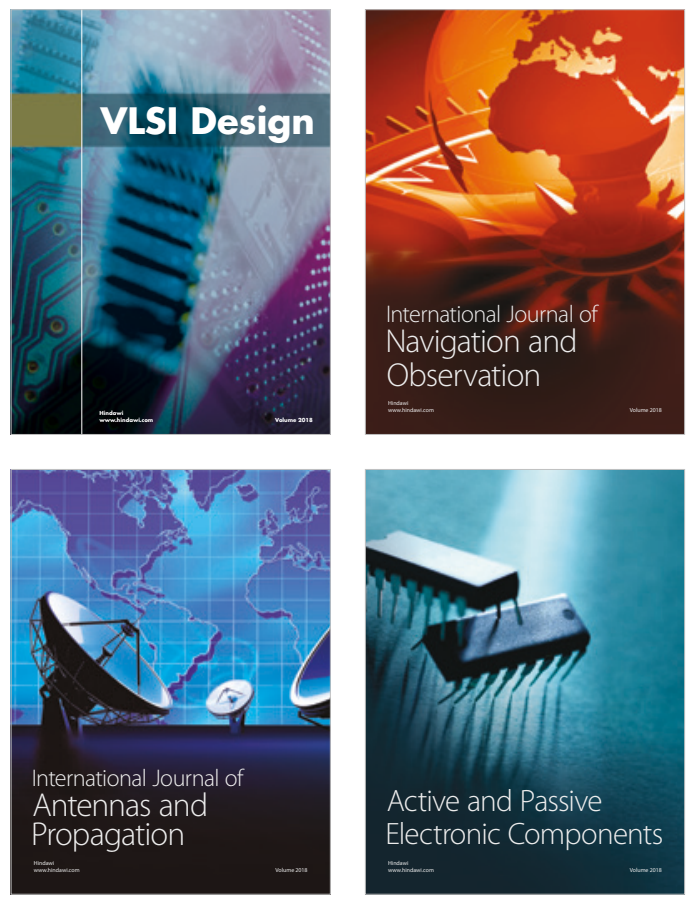
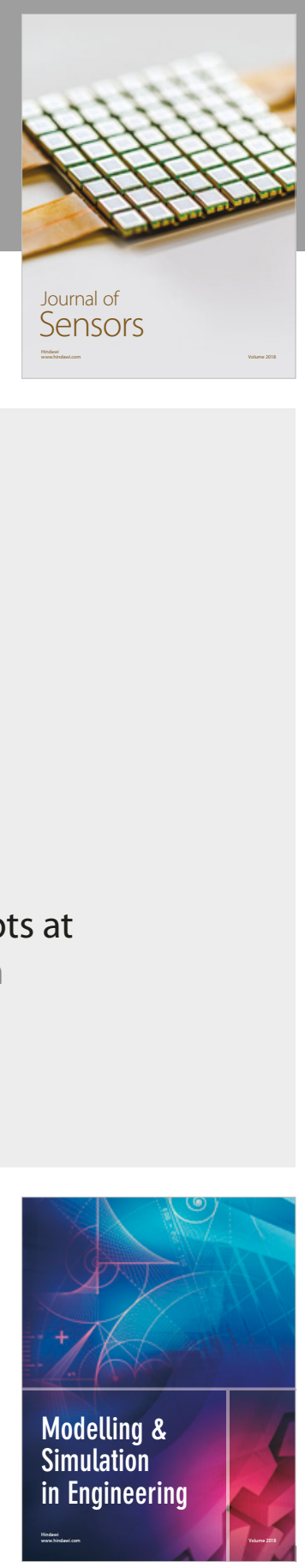

\section{Advances \\ Multimedia}
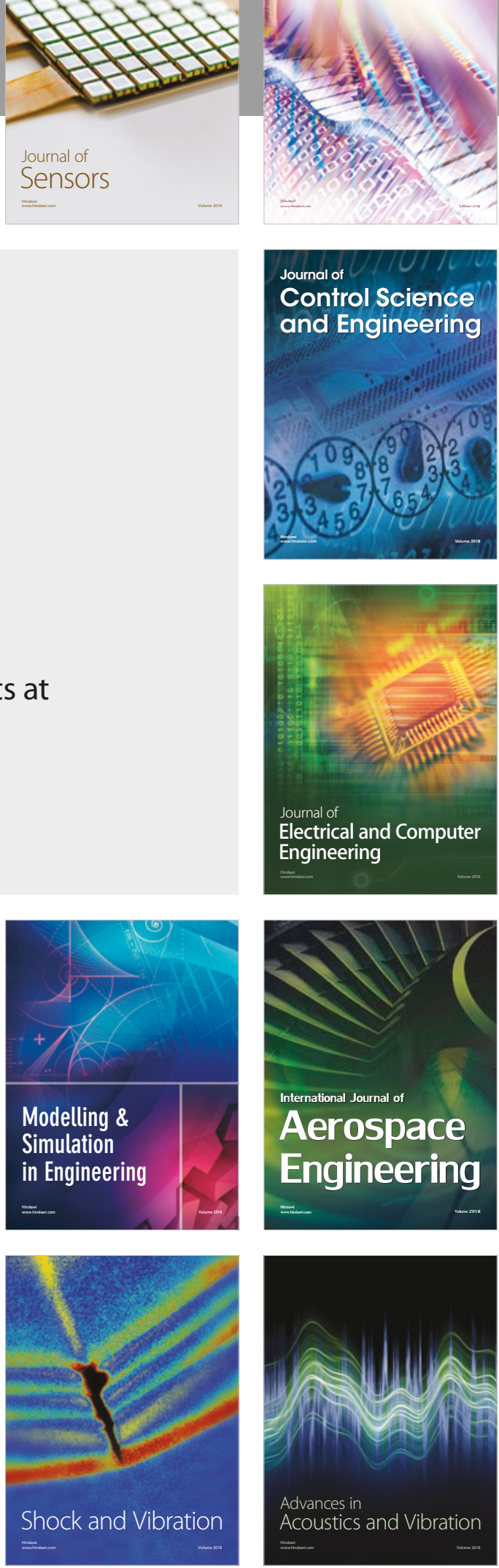